\title{
A preliminary evaluation of matricaria maritimum fibres for polymer reinforcement
}

\author{
P. Davies ${ }^{a, *}$, A. Bourmaud ${ }^{b}$, A. Pajot ${ }^{c}$ and C. Baley ${ }^{b}$
}

\begin{abstract}
a IFREMER Centre de Brest, Materials and Structures Group, BP70, 29280 Plouzané, France
b LIMATB Laboratoire d'Ingénierie des Matériaux de Bretagne, Equipe Polymères et Composites, Rue de Saint Maudé BP 92116, 56321 Lorient, France

${ }^{\mathrm{c}}$ Setalg, Presqu'ile de Pen Lan, BP24, 22610 Pleubian, France
\end{abstract}

*: Corresponding author : Peter Davies, Tel.: +33 298224777 ; email address : peter.davies@ifremer.fr

\begin{abstract}
:
This short communication describes results from a preliminary characterization of the dimensions and mechanical properties of matricaria maritimum fibres. The aim is to develop a complementary industrial application of these plants, which are grown along the coast mainly for pharmaceutical use. The fibres are shown to be of small diameter, 5-10 $\mu \mathrm{m}$, and tubular in form. Nano-indentation on fibres and tensile tests on fibre bundles provide an indication of the mechanical behaviour of these fibres, which are similar to those of sisal (leaf fibre) and miscanthus (grass fibre), and may be interesting for reinforcement of polymer matrix composites.
\end{abstract}

\section{Highlights}

Properties of matricaria maritimum fibres appear interesting for composite reinforcement. Modulus values similar to sisal. Tubular shape may offer other advantages. C Combination with pharmaceutical applications may contribute to a more economical crop development.

Keywords : Natural fibre; Nano-indentation; Tensile properties 


\section{Introduction}

There is considerable current interest in natural fibres as reinforcement in biocomposites to replace traditional glass fibre reinforced plastics (Bledzki and Gassan, 1999). The most popular fibres are currently flax, hemp, jute, and sisal, but cellulose-based fibres can be found in many other plants and their properties may also be suitable for industrial applications. For example, previous studies have shown that sea grass fibres may provide useful stiffness enhancement (Davies et al. 2007). However, in order to be economically viable it is important to focus on plants which are already being grown for other uses, so that the fibres can be exploited as a value-adding by-product. For this reason various algues and halophytes (plants which grow in a saline environment) currently employed for the pharmaceutical industry have been examined. One of these, matricaria maritimum, was selected for further study as it appeared to contain small diameter, stiff fibres. This short communication presents first results from an evaluation of the mechanical properties of these fibres. It should be emphasized that these results are for plants from crops destined for extraction of products for the pharmaceutical industry and not selected on the basis of fibre content nor optimised in any way for mechanical applications.

\section{Materials and Methods}

Matricaria Maritimum or Tripleurospermum maritimum is a coastal asteraceae plant also known as sea mayweed. It grows to a height of about $60 \mathrm{~cm}$ and has white and yellow flowers similar to a large daisy. It is a bi-annual plant grown along the Brittany coastline (France), mainly for pharmaceutical use; the plants studied here were grown on the Atlantic coast of Finistère. Two batches of fibres were studied, from crops harvested in successive years. Plants were sown in March the first year, and harvested in September, followed by a new harvest in September of the following year. The first 
batch was dried after picking, the second was not, but both were subsequently soaked in water in the laboratory for seven days to facilitate fibre extraction.

In order to make sections for microscopy the stems were soaked in a water-ethanol mixture for 24 hours, to harden the fibres to avoid crushing them during cutting. Thin films $(<0.5 \mathrm{~mm}$ thick) were then sliced from the stem, cleaned and observed in an optical microscope.

Figure 1 shows a section through a plant stem from the bottom of the plant, the fibres are grouped in bundles around the outer surface (lighter coloured circular regions) in a similar way to flax, hemp and nettle fibres.

\section{Figure 1.}

Scanning electron microscopy revealed information on the fibre geometry, both in bundles Figure 2a, and individual fibres, Figure $2 \mathrm{~b}$.

Figure 2.

The fibres are roughly circular and exhibit a large lumen, significantly larger than those in fibres such as flax. Indeed the fibre geometry is closer to a tube than a solid fibre, with a wall thickness around 2 microns. The small outer diameter of these fibres, 5-10 $\mu \mathrm{m}$, make it difficult to extract them from plant stems for individual testing. Bundles of fibres were therefore removed from stems and their mechanical properties were examined using nano-indentation and tensile testing. This is of practical interest as bundles rather than separated fibres are generally used to reinforce bio-composites. The longitudinal nano-indentation measurements were made on the fibre sections after coating of stems in an epoxy thermoset resin and polishing to a $1-\mu \mathrm{m}$ particle size polishing solution finish. A three-sided pyramid (Berkovich) diamond indenter was used, with a continuous stiffness measurement (CSM) technique. Measurements were made with a 3-nm amplitude, $70 \mathrm{~Hz}$ oscillation using identical loading rate conditions 
$\left(0.05 \mathrm{~s}^{-1}\right)$ for all the samples. The influence of indentation depth was examined in a preliminary study and stabilized values were obtained for depths greater than $60 \mathrm{~nm}$. Measurements here were taken at depths to $120 \mathrm{~nm}$. Force and displacement were recorded and modulus values were determined based on the work of Oliver and Pharr (1992) Each measurement corresponds to a matrix of $10 \times 10$ indents, with $5 \mu \mathrm{m}$ between indents. This technique has been used in previous fibre studies, and full details can be found elsewhere (Bourmaud and Baley, 2009). Such measurements provide a first indication of the mechanical response of fibres; they do not provide traditional modulus values as the loading is a mixture of longitudinal and transverse modes. Nevertheless, as similar measurements have been made on various other fibres under the same conditions it provides a useful comparative guide to fibre stiffness during screening.

Tensile properties were then measured on fibre bundles bonded to cardboard windows as described in ASTM D3822. Tests were performed at $1 \mathrm{~mm} / \mathrm{minute}$ on two test machines with $2 \mathrm{~N}$ and $18 \mathrm{~N}$ load cells. Crosshead displacement was corrected for machine compliance to determine strain. Bundle cross-sections were measured by microscopy on each sample and an equivalent diameter was used to determine stress. Identical tests have been performed previously on flax fibre bundles of similar size.

\section{Results and Discussion}

Figure 3 shows results from indentation tests, together with values for flax fibres. These indicate that the indentation stiffness of these matricaria maritimum fibres is roughly half that of flax. The average longitudinal modulus of matricaria maritimum from nanoindentation tests is $10.7 \pm 1.6 \mathrm{GPa}$. This value could be compared with nanoindentation modulus obtained for various vegetal fibers by using the same method. In a previous 
study (Bourmaud and Pimbert, 2008) the nano-indentation modulus values for miscanthus, flax, hemp and sisal fibers were 9.49 $\pm 1.21 \mathrm{GPa}, 17.97 \pm 1.61 \mathrm{GPa}, 12.14$ $\pm 2.26 \mathrm{GPa}$ and $8.52 \pm 1.72 \mathrm{GPa}$ respectively. The matricaria maritimum modulus is thus similar to those of sisal and miscanthus fibres.

The secondary cell walls of plant fibres (the S2 layer) are composed of highly crystalline cellulose fibrils spirally wound in a matrix of amorphous hemi cellulose and lignin. As the stiffness of the cellulose fibrils is about 30 times greater than those of the hemicellulose and lignin [6], the quantity and orientation of cellulose fibrils strongly influence the measured Young's modulus value. The cellulose content is around 6575\% for flax fibers (Baley, 2002) and only $46 \%$ in miscanthus fibers (Kaack et al 2003). Further work is needed to characterize the structure of matricaria fibres.

Due to the large anisotropy between transverse and longitudinal properties and to the loading mode (Gindl et al. 2008), the modulus values from nano-indentation are considerably lower than the tensile test values. Indeed, the tensile moduli presented in the literature are $58 \pm 15 \mathrm{GPa}$ for flax (Baly, 2002), $35 \mathrm{GPa}$ for hemp (Nabi-Saheb and Jog, 1999) and 9-22 GPa for sisal (Li et al. 2000).

\section{Figure 3.}

Tensile testing of fibre bundles resulted in stress-strain plots such as those shown in Figure 4. Their response is quite linear up to failure. Table 1 summarizes measured properties, together with values for flax bundles and single fibres tested under identical conditions.

\section{Figure 4.}

Table 1 :

There is considerable variation in properties, as is generally found in tests on this type of fibre (Andersons et al. 2005, Charlet et al. 2007). Results from the two matricaria 
batches differ, the first batch is stiffer and more brittle than the second, suggesting that it may be possible to optimise the properties. Once again the stiffness values are roughly half those of flax fibres, which are generally considered to have the best mechanical performance of the natural fibres used today. Given the indentation values, and the ratio between matricaria and flax bundles and the bundle/single fibre ratio the matricaria single fibre stiffness is probably close to those of sisal single fibres. These values are interesting, particularly as these fibres were taken from plants developed for other applications. The small diameter and tubular nature of the fibres may bestow other interesting properties, there has been considerable research into tubular carbon fibres to reduce weight and improve compression behaviour (Wang et al. 1998). The fibres in the plants tested here tend to be rather short, around 5mm, which is suitable for compounds used in injection moulding but shorter than the fibres used in laminated composite reinforcement. Work is continuing on these and other fibres from marine and coastal plants, to examine how properties vary with growth conditions and species.

\section{Acknowledgements.}

The contributions of Samuel Le Coq, Margaux Pourret and Pierre Guéret to this work are gratefully acknowledged.

\section{References}

Andersons J., Sparnins E., Joffe R., Wallström L., 2005. Strength distribution of elementary flax fibres. Composites Science and Technology, 65, 693-702.

Baley C., 2002. Analysis of the flax fibres tensile behaviour and analysis of the tensile stiffness increase. Composites Part A: Applied Science and Manufacturing, 33, 939-48. Bledzki A.K., Gassan J., 1999. Composites reinforced with cellulose based fibres. Progress in Polymer Science. 24, 221-74.

Bourmaud A., Pimbert S., 2008. Investigations on mechanical properties of poly(propylene) and poly(lactic acid) reinforced by miscanthus fibers. Composites Part A: Applied Science and Manufacturing, 39, 1444-54.

Bourmaud A., Baley C., 2009. Rigidity analysis of polypropylene/vegetal fibre composites after recycling. Polymer Degradation and Stability. 94, 297-305. 
Bourmaud A, Morvan C, Baley C. Importance of fiber preparation to optimize the surface and mechanical properties of unitary flax fiber. Industrial Crops and Products. 2010, 32:662-7.

Charlet K., Baley C., Morvan C., Jernot J.P., Gomina M., Bréard J., 2007.

Characteristics of Hermès flax fibres as a function of their location in the stem and properties of the derived unidirectional composites. Composites Part A: Applied Science and Manufacturing. 38, 1912-21.

Davies P., Morvan C., Sire O., Baley C., 2007. Structure and properties of fibres from sea-grass (Zostera marina). Journal of Materials Science. 42, 4850-7.

Gindl W., Reifferscheid M., Adusumalli R-B., Weber H., Röder T., Sixta H. , Schöberl T., 2008. Anisotropy of the modulus of elasticity in regenerated cellulose fibres related to molecular orientation. Polymer. 49, 792-9.

Kaack K., Schwarz K-U., Brander P.E., 2003. Variation in morphology, anatomy and chemistry of stems of Miscanthus genotypes differing in mechanical properties.

Industrial Crops and Products. 17, 131-42.

Li Y., Mai Y-W., Ye L., 2000. Sisal fibre and its composites: a review of recent developments. Composites Science and Technology. 60, 2037-55.

Nabi-Saheb D., Jog JP., 1999. Natural fiber polymer composites: A review. Advances in Polymer Technology. 18, 351-63.

Oliver W.C. and Pharr G.M., 1992. An improved technique for determining hardness and elastic modulus using load and displacement sensing indentation experiments. $\mathbf{J}$ Mat Res. 17, 1564-83.

Wang C., Li M., Wu Y., Guo C., 1998. Preparation and microstructure of hollow mesophase pitch-based carbon fibers. Carbon. 36, 1749-54.

\begin{tabular}{ccccc}
\hline Fibre & $\begin{array}{c}\text { Diameter } \\
(\mu \mathrm{m})\end{array}$ & $\begin{array}{c}\text { Modulus E } \\
(\mathrm{GPa})\end{array}$ & $\begin{array}{c}\text { Break stress } \\
(\mathrm{MPa})\end{array}$ & $\begin{array}{c}\text { Break } \\
\text { strain (\%) }\end{array}$ \\
\hline $\begin{array}{c}\text { Matricaria (bundles) } \\
\text { Batch 1 }\end{array}$ & $101 \pm 59$ & $15.8 \pm 5.2$ & $154 \pm 87$ & $1.6 \pm 0.6$ \\
\hline $\begin{array}{c}\text { Matricaria } \text { (bundles) } \\
\text { Batch 2 }\end{array}$ & $93 \pm 47$ & $7.9 \pm 3.9$ & $235 \pm 155$ & $2.5 \pm 0.5$ \\
\hline $\begin{array}{c}\text { Flax (bundles) } \\
\text { (Alix et al 2009) }\end{array}$ & $84 \pm 20$ & $30 \pm 11$ & $300 \pm 100$ & $1.1 \pm 0.4$ \\
\hline $\begin{array}{c}\text { Flax (single fibres) } \\
\text { (Bourmaud et al 2010) }\end{array}$ & $15.8 \pm 4.5$ & $51.1 \pm 15.0$ & $808 \pm 340$ & $1.6 \pm 0.4$ \\
\hline $\begin{array}{c}\text { Sisal (single fibres) } \\
\text { (Bourmaud \& Baley 2009) }\end{array}$ & $25.4 \pm 11.2$ & $25.0 \pm 12.9$ & $526 \pm 290$ & $2.3 \pm 0.4$ \\
\hline
\end{tabular}

Table 1 : Tensile properties of matricaria maritima compared to flax and sisal fibres 


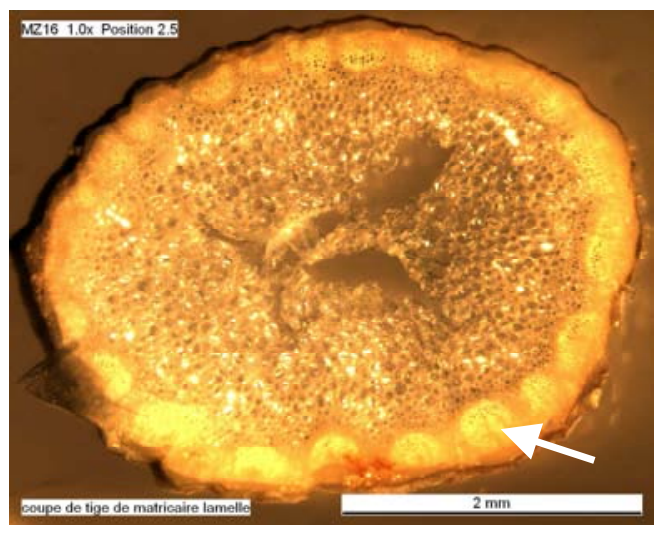

Figure 1. Section though plant stem, optical microscope, fibre bundle indicated by arrow

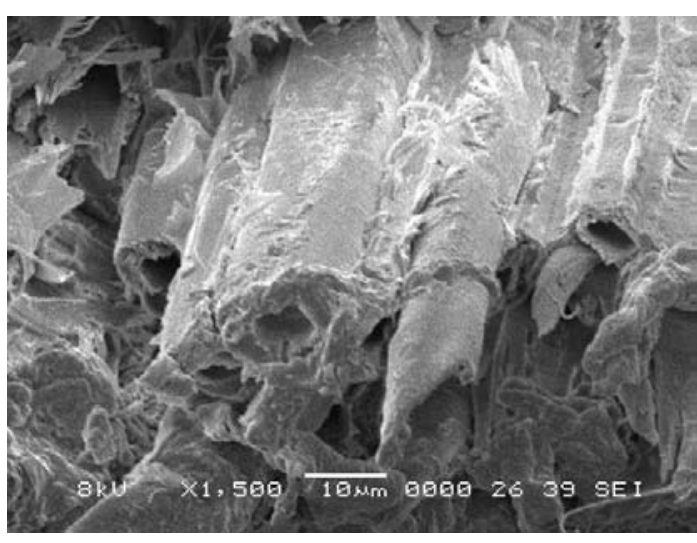

(a)

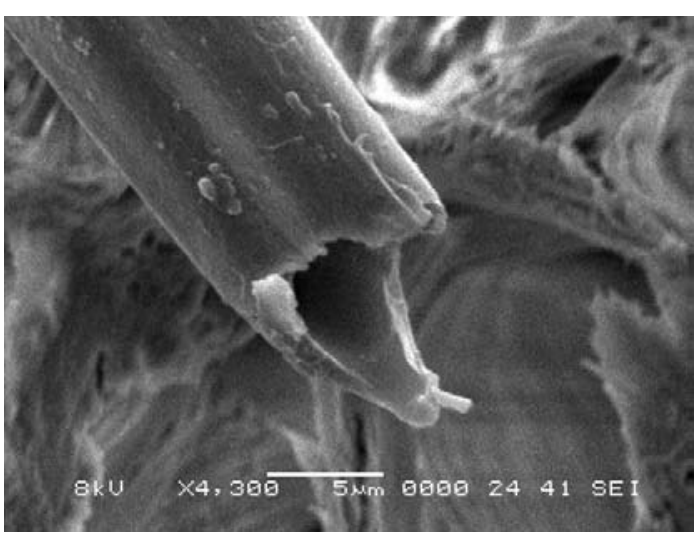

(b)

Figure 2. Scanning electron microscope images, a) Fibre bundle, b) Individual fibre.

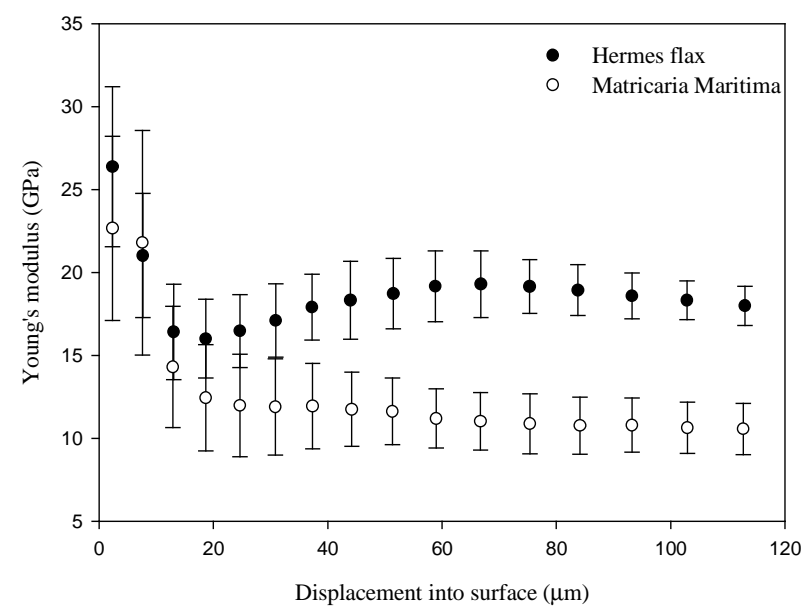

Figure 3. Nano-indentation measurements for matricaria and flax fibres. 


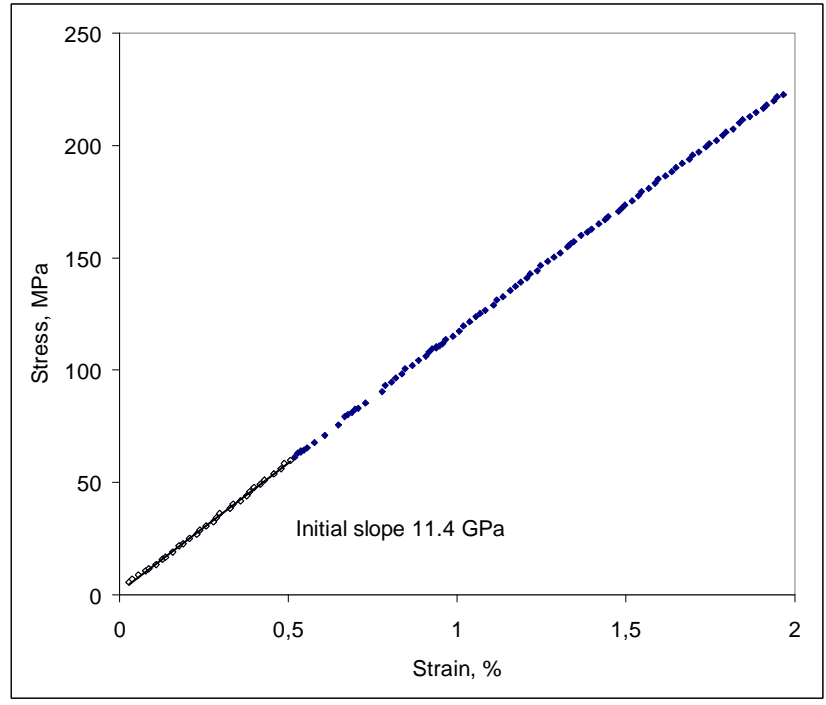

Figure 4. Example of tensile test plot for matricaria maritimum fibre bundle. 